\title{
Author Correction: The morphology, molecular development and ecological function of pseudonectaries on Nigella damascena (Ranunculaceae) petals
}

Hong Liao, Xuehao Fu (1), Huiqi Zhao, Jie Cheng (D), Rui Zhang, Xu Yao (D), Xiaoshan Duan, Hongyan Shan \& Hongzhi Kong (D)

Correction to: Nature Communications https://doi.org/10.1038/s41467-020-15658-2, published online 14 April 2020.

In the original version of the Article, there were typographical errors in the Abstract and Discussion sections.

In the original Abstract, the gene 'NidaYABB5' was missing a Y and should have been NidaYABBY5.

In the first paragraph of the Discussion, the sentence 'Specifically, being protrusive, colorful, and reflective make pseudonectaries...' should have read: 'Specifically, being protrusive, colorful, and reflective makes pseudonectaries...'.

In the fourth paragraph of the Discussion, the sentence 'Genes involved in nectar development, such as orthologs STY1/2 and LRP...' should have read: 'Genes involved in nectary development, such as orthologs of STY1/2 and LRP...'.

In the fourth paragraph of the Discussion, the sentence '...ectopic expression of NidaYAB5 can explain the reason why pseudonectaries was formed in the adaxial side of the lower lip of the petal' should have read: '...ectopic expression of NidaYAB5 can explain the reason why pseudonectaries were formed in the adaxial side of the lower lip of the petal'.

This has now been corrected in the PDF and HTML versions of the Article.

Published online: 06 May 2020

\footnotetext{
reproduction in any medium or format, as long as you give appropriate credit to the original author(s) and the source, provide a link to the Creative Commons license, and indicate if changes were made. The images or other third party material in this article are included in the article's Creative Commons license, unless indicated otherwise in a credit line to the material. If material is not included in the article's Creative Commons license and your intended use is not permitted by statutory regulation or exceeds the permitted use,
} you will need to obtain permission directly from the copyright holder. To view a copy of this license, visit http://creativecommons.org/licenses/by/4.0/. 